\title{
Erratum to: National estimates of blood lead, cadmium, and mercury levels in the Korean general adult population
}

\author{
Nam-Soo Kim $\cdot$ Byung-Kook Lee
}

Published online: 21 August 2010

(C) Springer-Verlag 2010

\section{Erratum to: Int Arch Occup Environ Health \\ DOI 10.1007/s00420-010-0522-6}

In the original publication of this article, four numeric values were wrong in the "Quality assurance and control" section. The right ones are found in bold in the following paragraph.

\section{Quality assurance and control}

All blood heavy-metal analyses were carried out by Seoul Medical Science Institute (SMSI), a laboratory certified by the Korean Ministry of Health and Welfare. For the internal quality assurance and control program, commercial reference materials were obtained from Bio-RAD (Lyphochek [1] Whole Blood Metals Control), which showed that the coefficients of variation were $\mathbf{8 . 2 \%}$ for three blood lead samples (reference values: 8.5, 26.0, and $\mathbf{4 8 . 0} \mu \mathrm{g} / \mathrm{dL}$ ), $14.5 \%$ for three blood cadmium samples (reference values: $0.37,1.11$, and $4.30 \mu \mathrm{g} / \mathrm{L}$ ), and $8.3 \%$ for three blood mercury samples (reference values: 4.7, 36.8, and $68.7 \mu \mathrm{g} / \mathrm{L}$ ).

The online version of the original article can be found under doi: 10.1007/s00420-010-0522-6.

N.-S. Kim · B.-K. Lee $(\square)$

Institute of Environmental and Occupational Medicine,

College of Medicine, Soonchunhyang University, 646 Eupnae-ri,

Shinchang-myun, Asan, Choongnam 336-745, Korea

e-mail: bklee@sch.ac.kr 